\title{
BIBLIOMETRIA DA PESQUISA BRASILEIRA EM EROSÃO ACELERADA DO SOLO: INSTITUIÇÕES, TEMAS, ESPAÇO E CRONOLOGIA ${ }^{(1)}$
}

\author{
Alberto Giaroli de Oliveira Pereira Barretto( ${ }^{(2)}$, Jane Siqueira \\ Lino $^{(3)} \&$ Gerd Sparovek $^{(4)}$
}

\begin{abstract}
RESUMO
Apesar do constante aumento na quantidade e diversidade de publicações acerca da erosão do solo no Brasil e no mundo, as grandes questões dessa ciência ainda não foram respondidas. Os possíveis motivos desse descompasso trazem à tona a necessidade de discutir o papel da pesquisa em erosão. A bibliometria permite uma visão abrangente da ciência, fornecendo perspectivas, contudo estudos que fazem uso dessas técnicas são escassos no mundo, bem como no Brasil. Os objetivos deste trabalho foram analisar as distribuições espacial, temporal, institucional e temática da pesquisa brasileira em erosão acelerada do solo a partir da divisão dos artigos em linhas temáticas e discutir a profundidade da abordagem das questões fundamentais em erosão. Para isso, 225 artigos de instituições brasileiras cujo tema central é a erosão do solo foram digitalizados, cadastrados em banco de dados e classificados em cinco linhas temáticas. Também foram produzidos mapas multitemporais a partir de ferramentas de geoprocessamento. A pesquisa brasileira em erosão, além de recente, está concentrada: (a) em poucas instituições, localizadas nas regiões Sul e Sudeste; e (b) em dois temas, centrados na Equação Universal de Perda de Solo e em comparações de manejos agrícolas quanto à perda de solo, com grande influência do nível de consolidação dos núcleos de pesquisa, que têm nesses dois temas centrais sua iniciação na pesquisa em erosão acelerada do solo.
\end{abstract}

Termos de indexação: erosão hídrica, banco de dados, história.

\footnotetext{
${ }^{(1)}$ Programa de Pós-Graduação em Solos e Nutrição, Escola Superior de Agricultura "Luiz de Queiroz" - ESALQ/USP. Recebido para publicação em outubro de 2008 e aprovado em julho de 2009.

(2) Programa de Pós-Graduação em Solos e Nutrição de Plantas, Escola Superior de Agricultura "Luiz de Queiroz" - ESALQ/USP. Caixa Postal 9, Av. Pádua Dias 11, CEP 13418-900 Piracicaba (SP). E-mail: barretto.alberto@gmail.com

(3) Programa de Pós-Graduação em Solos e Nutrição de Plantas, ESALQ/USP. E-mail: janesiqueiralino@gmail.com

(4) Professor do Departamento de Solos e Nutrição de Plantas, ESALQ/USP. E-mail: gerd@esalq.usp.br
} 


\title{
SUMMARY: BIBLIOMETRICS INBRAZILIANRESEARCH ONACCELERATED SOIL EROSION: INSTITUTIONS, TOPICS, SPACE AND CHRONOLOGY
}

\begin{abstract}
Despite the increasing number and diversity of publications related to soil erosion in Brazil and throughout the world, the central questions of this science remain unanswered. The possible reasons for this imbalance highlight the need to reconsider the role of research on soil erosion. Bibliometric studies can provide ample view of the research field, describing perspectives, but research using this approach is scarce in international as well as in Brazilian literature. The objective of this study was to analyze the spatial, temporal, institutional and topical distribution of Brazilian research on accelerated soil erosion based on the organization of articles according to thematic lines and to discuss the depth of the approach to the fundamental issues of erosion in order to establish a bibliometric perspective. For this purpose, 225 articles of Brazilian institutions focused on soil erosion were scanned, registered in a database and classified into five thematic lines. Besides, multi-temporal maps were drawn using GIS tools. Brazilian research on erosion is recent and is characterized by: (a) concentration in few institutions in the southern and southeastern Brazil, (b) focused on two issues, related to the Universal Soil Loss Equation and comparisons of agricultural managements as related to soil loss, with a considerable influence of the consolidation level of the research centers, which have developed research on accelerated soil erosion along these two lines.
\end{abstract}

Index terms: water erosion, database, history.

\section{INTRODUÇÃO}

A preocupação com a conservação do solo indissociável do interesse em controlar os processos erosivos - desempenha importante papel no novo contexto da ciência do solo, voltado às questões ambientais em caráter multidisciplinar, e contribuiu sobremaneira para o aumento do número de publicações nessa ciência em todo o mundo (Yaalon \& Arnold, 2000).

Apesar de periféricas ao desenvolvimento da ciência do solo no princípio do século XX (Sanchez, 1972), as comunidades científicas de países tropicais têm apresentado crescente e ativa participação no cenário mundial, justificando uma análise cautelosa dessa participação por ferramentas específicas (Arvanitis \& Chatelin, 1994). O Brasil, por exemplo, ocupa o $12^{\circ}$ lugar mundial em publicação de artigos científicos sobre erosão e conservação do solo, segundo consulta à base ISI - Web of knowledge ${ }^{\circledR}$, realizada em 20/08/ 2008.

Entretanto, estudos que investiguem o desenvolvimento e as tendências da pesquisa em ciência do solo e, mais especificamente, em erosão do solo são raros e esparsos. Boardman (2006) afirma que, apesar dos diferentes enfoques dados à pesquisa em erosão, as grandes questões dessa ciência ainda não foram respondidas; além disso, a avaliação estritamente física dos processos erosivos dificulta o estabelecimento de relações entre a ciência e stake holders.

As motivações que podem explicar a dinâmica quantitativa e qualitativa da produção científica em erosão do solo trazem à tona a necessidade e a oportunidade de se discutir o papel da pesquisa em erosão e refletir seu futuro a partir da análise de seu desenvolvimento. A bibliometria apresenta-se como importante ferramenta para tal fim, permitindo obter visão abrangente da ciência, explicando os padrões de organização do seu conhecimento e fornecendo perspectivas a cada cientista e à comunidade científica (Arvanitis \& Chatelin, 1994). Destacam-se como estudos com uso dessas ferramentas a compilação de artigos sobre as tendências da ciência do solo feita por McDonald (1994) e a análise dos 100 volumes da revista Geoderma publicados entre 1967 e 2001 por Hartemink (2001). No Brasil, merece destaque a contribuição de Barretto et al. (2008), que adaptaram ferramentas computacionais de banco de dados e análises geográficas ao tema erosão acelerada do solo, com ênfase em artigos nacionais e internacionais de autores brasileiros. O presente trabalho analisou a produção brasileira de artigos científicos sobre a erosão acelerada do solo segundo sua distribuição temporal, espacial e temática.

\section{MATERIAL E MÉTODOS}

A fim de analisar em termos espaciais e temporais a pesquisa brasileira em erosão, foram utilizados artigos publicados por pesquisadores vinculados a instituições de pesquisa brasileiras de julho de 1949 a abril de 2007 em periódicos nacionais ou internacionais que estivessem indexados na base de dados Web of Science $^{\circledR}$ (ISI) ${ }^{(5)}$ e cujo tema central fosse erosão acelerada do solo. Um total de 225 artigos foi coletado,

\footnotetext{
(5) A única exceção a essa regra foi a Revista Bragantia, editada pelo Instituto Agronômico de Campinas. Esse periódico foi incluído mesmo não sendo indexado pela Base ISI, em razão do seu significativo valor histórico, já que essa é a única fonte de artigos relacionados à pesquisa brasileira em erosão do solo antes de 1977.
} 
digitalizado e cadastrado em um modelo de banco de dados construído no Microsoft Access 2003 ${ }^{\circledR}$, permitindo armazenar as informações necessárias à caracterização de elementos bibliográficos, sendo os principais: autoria; ano de publicação; periódico; título; instituição a que pertence o autor principal; e linha temática abordada.

A definição das linhas temáticas nas quais se dividem os estudos em erosão foi feita a partir de uma análise sistemática de cada artigo, definindo suas características principais, como objetivos, embasamento teórico e métodos utilizados. As diversas abordagens específicas foram agrupadas em cinco linhas temáticas excludentes entre si, a saber: (a) comparações entre diferentes manejos do solo; (b) aplicação e cálculo dos fatores da USLE (Equação Universal de Perda de Solo); (c) outros modelos e métodos de predição de erosão; (d) apresentação e avaliação de novas análises e técnicas de controle de erosão; e (e) abordagens diferenciadas das anteriores do tema erosão do solo.

Para facilitar as posteriores análises de distribuição de frequência de publicações ao longo do tempo, os dados de publicação foram separados por década, a partir da década de 1950, que englobou o ano de 1949, até os anos 2000, em que se dispôs de dados referentes até ao ano de 2007. A distribuição espacial, por sua vez, teve neste estudo dois tipos de análise. A primeira considerou a produção das principais instituições, selecionadas a partir de um critério de no mínimo 15 artigos publicados em que a instituição figurasse como primeira autora. A outra análise foi feita a partir de mapas multitemporais gerados por ferramentas de geoprocessamento, ilustrando a cronologia e a distribuição das publicações cadastradas entre os municípios das instituições autoras no Brasil, segundo a linha temática central.

\section{RESULTADOS E DISCUSSÃO}

Além de recente, a pesquisa brasileira em erosão acelerada do solo está concentrada em poucas instituições, localizadas principalmente nas regiões Sul e Sudeste. Na figura 1 são apresentadas as instituições sedes de pesquisas focadas na erosão, em ordem decrescente do total de artigos em que foram autoras principais, com destaque para as cinco instituições com maior número de publicações, representando $53 \%$ do total: Universidade Federal do Rio Grande do Sul (UFRGS); Universidade de São Paulo (USP), incluindo todas as suas unidades; Instituto Agronômico de Campinas (IAC); Universidade do Estado de Santa Catarina (UDESC); e Empresa Brasileira de Pesquisa Agropecuária (Embrapa), incluindo todas as suas unidades.

O IAC inaugurou a pesquisa brasileira sobre erosão acelerada do solo entre 1950 e 1970, que resultou em artigos de síntese baseados em longos períodos de experimentação. A partir da década de 1970, o IAC continua a ter presença institucional significativa, mas a produção de outros centros de pesquisa passa a ter importância relativa maior no conjunto. A partir de 1970, firmou-se como núcleo de referência no tema a Universidade Federal do Rio Grande do Sul (UFRGS), com produção crescente e acumulando o maior número de artigos em erosão acelerada do solo. Na década de 1980 são definitivamente determinados os dois polos geográficos mais representativos em produção científica sobre erosão acelerada do solo, ou seja, a pesquisa conduzida pela região Sudeste, representada pelo IAC e posteriormente pela USP e grande parte das unidades da Embrapa consideradas, e a pesquisa conduzida na região Sul, representada principalmente pela UFRGS e UDESC.

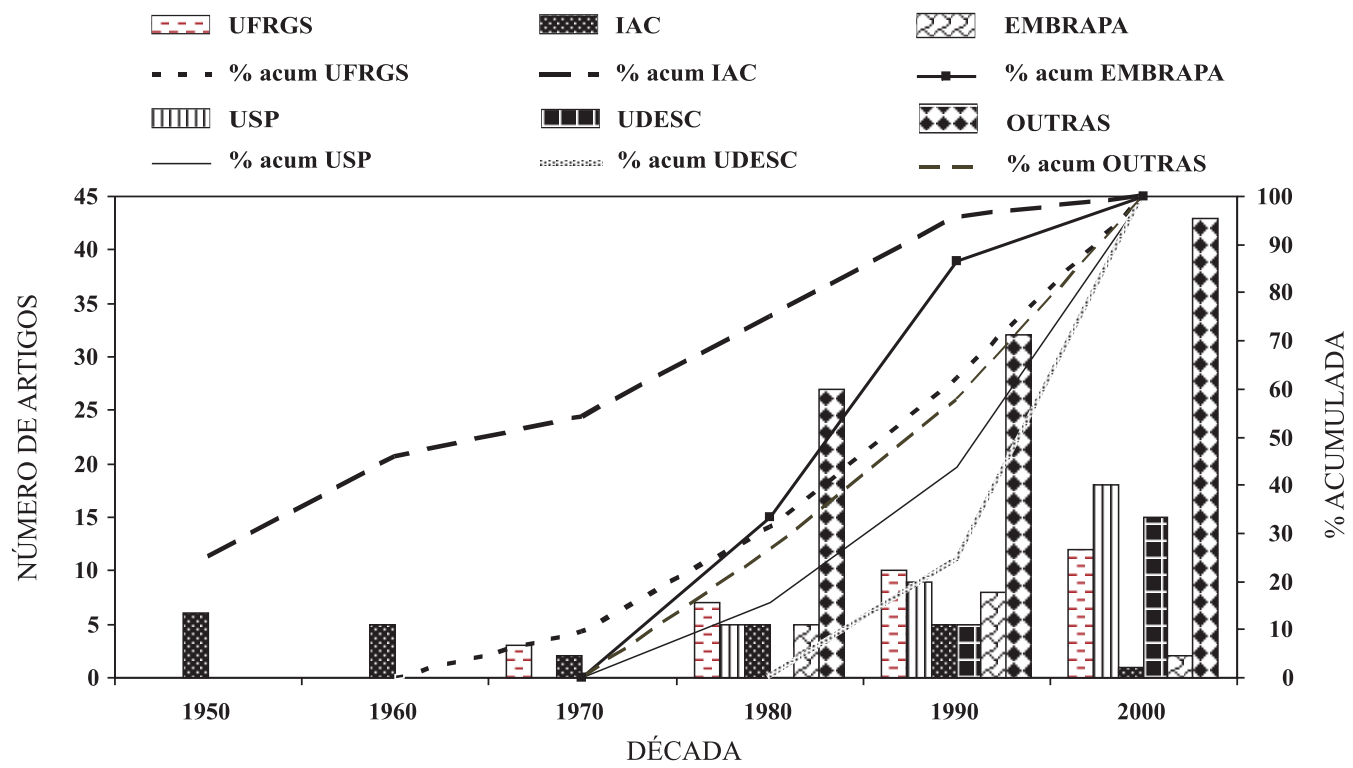

Figura 1. Produção científica (número de artigos e percentagem acumulada) sobre erosão acelerada do solo das principais instituições brasileiras ao longo do tempo. 
A década de 1980 foi marcada pelo início e aumento da participação de outras instituições, mantendo-se, porém, a concentração no eixo Sul-Sudeste. Entre elas, a USP destaca-se com o segundo maior número de publicações, cuja maioria foi desenvolvida na Escola Superior de Agricultura Luiz de Queiroz (ESALQ). A Embrapa configura-se num caso específico nessa lista, pois, além de possuir ampla variedade de temas de pesquisa, distribui-se em centros por todo o território brasileiro, havendo a contribuição de sete deles, que se localizam em diferentes Estados. Apesar da abrangência nacional, esse fato não descaracteriza a concentração espacial da pesquisa em erosão nas regiões Sul e Sudeste.

Além da concentração temporal, em virtude de sua história recente, e espacial, devido à maior contribuição por parte de poucas instituições e regiões no Brasil, a pesquisa em erosão tampouco possui distribuição homogênea em relação às temáticas abrangidas e aos métodos utilizados. No quadro 1 encontram-se as cinco principais linhas temáticas dentro da pesquisa em erosão e suas principais abordagens, bem como a quantidade e proporção de artigos publicados em cada uma delas.
Exceto na linha temática "Outros", em todas as demais os objetivos foram quantificar, comparar ou minimizar o montante de solo perdido em virtude da prática agrícola, baseando-se quase sempre em modelos matemáticos de aproximação. Contudo, as abordagens das publicações convergem principalmente para duas linhas: o cálculo e estimativa dos fatores da Equação Universal de Perda de Solo (USLE) e a comparação experimental entre diferentes manejos e coberturas na perda de solo por erosão ("Comp"), concentrando, juntas, mais de dois terços das publicações (Figura 2). Essa concentração nesses dois temas é bastante influenciada pelo histórico da pesquisa em erosão no Brasil, do surgimento à consolidação dos núcleos de pesquisa.

A pesquisa em erosão teve origem e enfoque distintos. Na Europa, os estudos surgiram a partir das ciências da geologia e geomorfologia e tinham como enfoque o conhecimento das características físicas do solo e da paisagem. Nos Estados Unidos, surgiu da necessidade de teorizar os experimentos agrícolas largamente empregados a fim de compreender e conter o processo erosivo. No Brasil, os primeiros artigos sobre erosão, publicados pelo IAC,

Quadro 1. Quantidade e proporção de artigos sobre erosão do solo, em função das linhas temáticas e suas diferentes abordagens

\begin{tabular}{|c|c|c|c|}
\hline \multicolumn{4}{|c|}{ Distribuição dos artigos nas linhas temáticas } \\
\hline Linha temática & Abordagem & $\mathrm{N}^{\circ}$ de artigos & Proporção \\
\hline \multirow{4}{*}{ COMP (Comparações) } & & & $\%$ \\
\hline & Diferentes manejos e perda de solo & 58 & 25,8 \\
\hline & Perdas de nutrientes, solo e água & 11 & 4,9 \\
\hline & Comparações com outros objetivos & 11 & 4,9 \\
\hline Subtotal & & 80 & 35,6 \\
\hline USLE (Equacão & Fator erosividade & 35 & 15,6 \\
\hline \multirow[t]{4}{*}{ Universal de Perda de Solo) } & Fator erodibilidade & 25 & 11,1 \\
\hline & Fator cobertura vegetal & 8 & 3,6 \\
\hline & Fator comprimento de rampa & $\begin{array}{l}0 \\
2\end{array}$ & 0,9 \\
\hline & Aplicações e validação & 5 & 2,2 \\
\hline Subtotal & & 75 & 33,3 \\
\hline OUTROS & Produtividade do solo e das culturas & 10 & 4,4 \\
\hline \multirow[t]{4}{*}{ (outras abordagens da erosão) } & Tolerância à erosão & 4 & 1,8 \\
\hline & Concepção histórica (erosão no tempo) & 4 & 1,8 \\
\hline & Concepção espacial (variabilidade e distribuição) & 4 & 1,8 \\
\hline & Alteração climática e sequestro de carbono & 3 & 1,3 \\
\hline Subtotal & & 25 & 11,1 \\
\hline PRÁTICAS & Obras de controle mecânico da erosão & 17 & 7,6 \\
\hline (controles-análises) & Métodos e modelos de análises físicas & 7 & 3,1 \\
\hline Subtotal & & 24 & 10,7 \\
\hline MODELOS & Césio 137 & 8 & 3,6 \\
\hline (modelagens e métodos & WEPP & 2 & 0,9 \\
\hline \multirow[t]{4}{*}{ de predição de erosão) } & SWATT & 2 & 0,9 \\
\hline & Outros modelos de predição & 3 & 1,3 \\
\hline & Comparações entre modelos & 2 & 0,9 \\
\hline & Novos índices e relações & 4 & 1,8 \\
\hline Subtotal & & 21 & 9,3 \\
\hline Total & & 225 & 100,0 \\
\hline
\end{tabular}




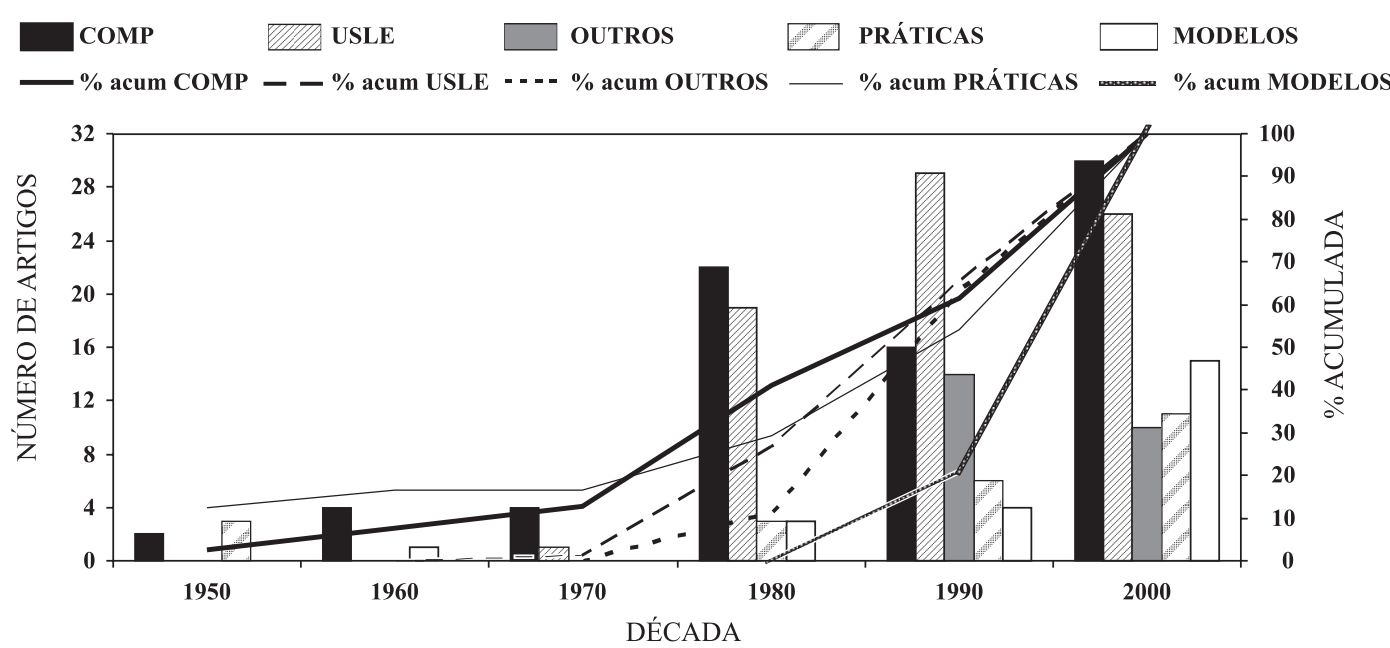

Figura 2. Evolução da quantidade e percentagem acumulada da produção de artigos nas principais linhas temáticas (COMP: comparação de sistemas de manejo; USLE: equação universal de perda do solo; OUTROS: outras abordagens da erosão; PRÁTICAS: análise de técnicas de controle de erosão; MODELOS: outras modelagens e métodos de predição de erosão) relativas à erosão no tempo.

denotam a influência da concepção norte-americana na formação da pesquisa em erosão, enfatizando a degradação do solo decorrente do continuado uso agrícola baseado em práticas que não tinham por premissa a conservação do solo. Esses estudos, em sua maioria, tinham por objetivo levar ao desenvolvimento de novas técnicas de manejo e métodos de avaliação - linha que teve declínio na década de 1960 para reaparecer em 1980 já com outro escopo, a ser analisado adiante. Esses estudos estão representados na figura 2 pela linha temática "Práticas".

Concomitantemente, a abordagem comparativa de diferentes técnicas de manejo e seus diferentes impactos nos processos erosivos figura 2 pela linha temática "Comp", também desempenhou importante papel no início da década de 1950, como consequência da influência exercida pela pesquisa norte-americana. Essa linha teve participação crescente na pesquisa em erosão no Brasil, mas principalmente promoveu o desenvolvimento de centros de pesquisa especializados em tal tipo de estudo, como a UFRGS (Quadro 2).

A elaboração da USLE, finalizada em 1964, passa a atrair o interesse da comunidade científica brasileira na década de 1970, dominando a produção de artigos na década de 1990 e sendo até hoje muito representativa. Seu principal foco é a quantificação dos fatores erosividade da chuva e erodibilidade do solo sob variados métodos e condições físicas, que respondem respectivamente por 15,6 e $11,1 \%$ das publicações (total de 26,7 \%). Esses enfoques, tomados até o início da década de 1980, moldaram os padrões nos quais se encaixaram as pesquisas subsequentes.

Apenas na década de 1990 começam a ser estudados outros modelos de predição de erosão (linha temática "Modelos"), como o modelo WEPP (Water Erosion
Prediction Project) e o uso do Césio 137, além de métodos qualitativos e elaboração de índices que permitem estimar a quantidade de erosão. Os esforços em conhecer o processo de erosão do solo por meio de modelos de predição são observados em 42,6 \% dos artigos publicados, enquanto a comparação entre diferentes formas de cultivo e testes para novas propostas de manejo agrupa 46,3 \% das publicações.

Novas abordagens sobre o tema erosão (linha temática "Outros") surgem na década de 1980 e caracterizam-se principalmente por não se comportarem como uma linha de pesquisa, e sim como a união de diferentes pontos de vista convertidos em artigos por diferentes instituições. Entre essas visões, puderam ser percebidas como principal a relação da perda de solo com a produtividade das culturas e a tolerância à perda, e como temas secundários, a relação com alterações climáticas e a espacialização da erosão.

Também na década de 1980 ressurgem artigos avaliando técnicas e métodos de controle da erosão, porém divergentes daqueles concebidos até a década de 1960. Nesse novo período houve a integração de programas computacionais para modelar cálculos e padronizar técnicas, além de uma rediscussão de parâmetros na avaliação de manejos anteriormente tidos como indiscutivelmente eficazes no controle da erosão. São exemplos desses novos temas: técnicas de avaliação do comportamento espectral dos solos, softwares que permitem trabalhar com dados georreferenciados, sistema de plantio direto como prática de controle de erosão, agricultura de precisão, entre outros.

A participação das cinco principais instituições analisadas em cada linha temática é bem acentuada, determinando também a variação da distribuição 
espacial das abordagens da pesquisa. Observou-se também, por vezes, a definição de linhas de pesquisa características para as instituições. No quadro 2 encontra-se, para cada tema, o número de artigos publicados de cada instituição, bem como o total de suas publicações. A fim de pormenorizar a discussão, em seguida são apresentados, nas figuras 3 a 7 , conjuntos de mapas multitemporais com as quantidades de artigos publicados por década nas diferentes linhas, utilizando como referência geográfica os municípios das instituições sedes de todos os trabalhos considerados para este estudo.

A semelhança entre a distribuição das publicações nas linhas temáticas (Quadro 1) e a proporção dos trabalhos nessas linhas pelas instituições mais atuantes (Quadro 2) comprova a representatividade dessas instituições para a análise da pesquisa em erosão feita em todo o Brasil. Todavia, outras instituições têm isoladamente contribuições importantes em determinada área, comportando-se como centros de pesquisa especializados em temas específicos da erosão do solo (Figuras 3 a 7).
A figura 3 mostra a distribuição espacial da pesquisa que aborda o tema comparações de manejo ("Comp"). Os artigos publicados nessa linha foram, em sua totalidade, restritos ao IAC até a década de 1970, quando a UFRGS consolidou-se como nova fonte desse tema, passando então, nas décadas de 1980 e 1990, a ter a autoria da maior parte dos artigos baseados em experimentos comparativos. Já em 2000 ascende a UDESC, com o maior pico de publicações registrado sobre esse tema, muito influenciada pelo trabalho desempenhado pela UFRGS. Além das cinco instituições analisadas, pesquisas comparativas foram também desenvolvidas principalmente em Pernambuco, pela Universidade Federal Rural de Pernambuco (UFRPE), em Minas Gerais, pela Universidade Federal de Lavras (UFLA), e no Rio Grande do Sul, pela Universidade Federal de Santa Maria (UFSM). Apesar de ser o tema mais pesquisado, o estudo comparativo de sistemas de manejo está centralizado em três instituições, que publicaram juntas $50 \%$ dos artigos analisados. A influência da história da pesquisa foi marcante na distribuição da publicação nessa linha tanto no caso do pioneiro IAC,

Quadro 2. Quantidade de artigos publicados por linha temática em cada instituição principal no tempo

\begin{tabular}{|c|c|c|c|c|c|c|c|c|}
\hline \multirow{3}{*}{ Tema } & \multicolumn{8}{|c|}{ Produção de artigos por linha e instituição no tempo } \\
\hline & \multirow[t]{2}{*}{ Instituição } & \multicolumn{6}{|c|}{ Décadas } & \multirow[t]{2}{*}{ Total geral } \\
\hline & & 1950 & 1960 & 1970 & 1980 & 1990 & 2000 & \\
\hline \multirow[t]{6}{*}{ COMP } & UFRGS & & & & 6 & 4 & 7 & 19 \\
\hline & USP & & & & & & 1 & 1 \\
\hline & IAC & 3 & 4 & 2 & 4 & 1 & 1 & 15 \\
\hline & UDESC & & & & & 2 & 10 & 12 \\
\hline & EMBRAPA & & & & 2 & 1 & & 3 \\
\hline & OUTRAS & & & & 10 & 8 & 11 & 29 \\
\hline COMP subtotal & & 3 & 4 & 4 & 22 & 16 & 30 & 79 \\
\hline \multirow[t]{6}{*}{ USLE } & UFRGS & & & 1 & 1 & 5 & 5 & 12 \\
\hline & USP & & & & 3 & 3 & 3 & 9 \\
\hline & IAC & & & & 1 & 3 & & 4 \\
\hline & UDESC & & & & & 3 & 4 & 7 \\
\hline & EMBRAPA & & & & 1 & 6 & 2 & 9 \\
\hline & OUTRAS & & & & 14 & 9 & 11 & 34 \\
\hline USLE subtotal & & & & 1 & 20 & 29 & 25 & 75 \\
\hline \multirow[t]{6}{*}{ OUTROS } & UFRGS & & & & & 1 & & 1 \\
\hline & USP & & & & & 4 & 3 & 7 \\
\hline & IAC & & & & & 1 & & 1 \\
\hline & UDESC & & & & & & 1 & 1 \\
\hline & EMBRAPA & & & & 1 & 1 & & 2 \\
\hline & OUTRAS & & & & 2 & 7 & 6 & 15 \\
\hline OUTROS subtotal & & & & & 3 & 14 & 10 & 27 \\
\hline \multirow[t]{4}{*}{ PRÁTICAS } & USP & & & & 1 & 1 & 4 & 6 \\
\hline & IAC & 3 & 1 & & & & & 4 \\
\hline & EMBRAPA & & & & 1 & & & 1 \\
\hline & OUTRAS & & & & 1 & 5 & 7 & 13 \\
\hline PRÁTICAS subtotal & & 3 & 1 & & 3 & 6 & 11 & 24 \\
\hline \multirow{2}{*}{ MODELOS } & USP & & & & 1 & 1 & 7 & 9 \\
\hline & OUTRAS & & & & & 3 & 8 & 11 \\
\hline MODELOS subtotal & & & & & 1 & 4 & 15 & 20 \\
\hline Total & & 6 & 5 & 5 & 49 & 69 & 91 & 225 \\
\hline
\end{tabular}




\section{DISTRIBUIÇÃO DA LINHA TEMÁTICA “COMP” NO BRASIL}
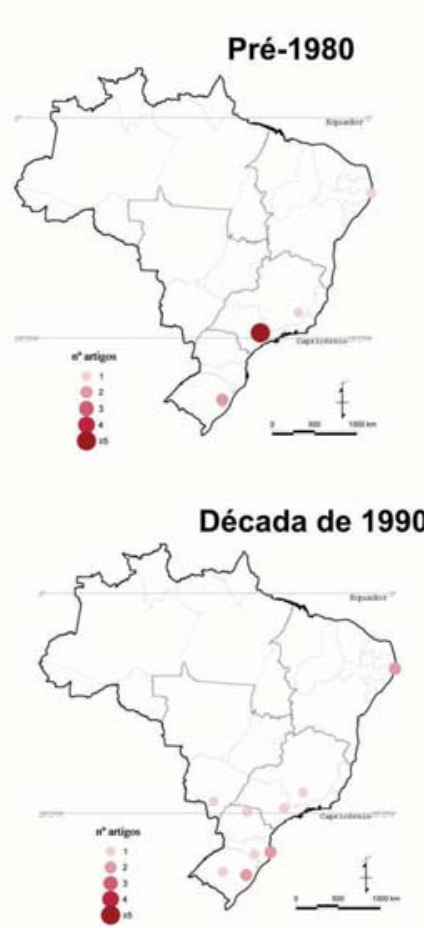
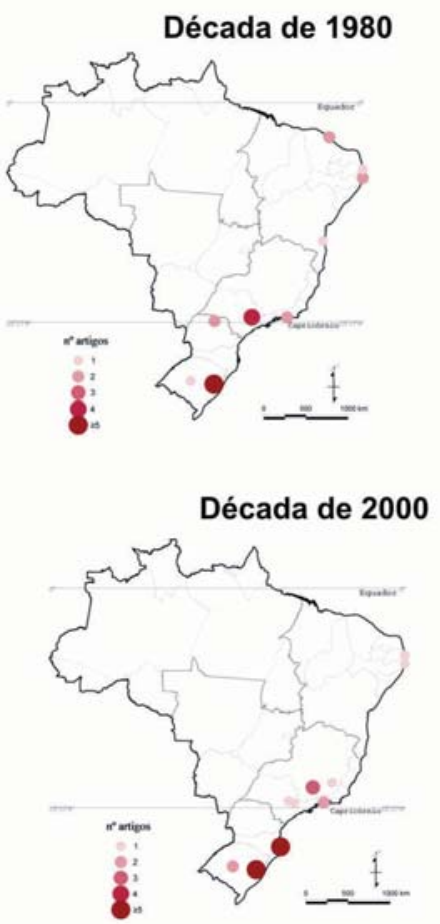

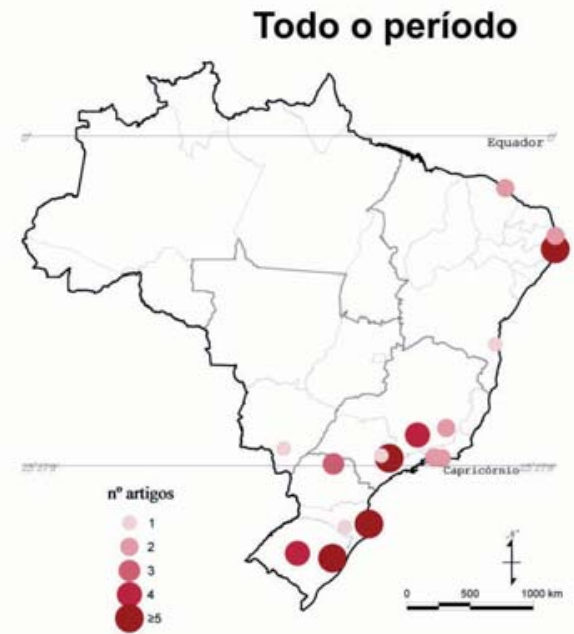

Figura 3. Distribuição espacial da produção de artigos na linha temática “COMP” (comparação de manejos) por década.

\section{DISTRIBUIÇÃO DA LINHA TEMÁTICA “USLE” NO BRASIL}
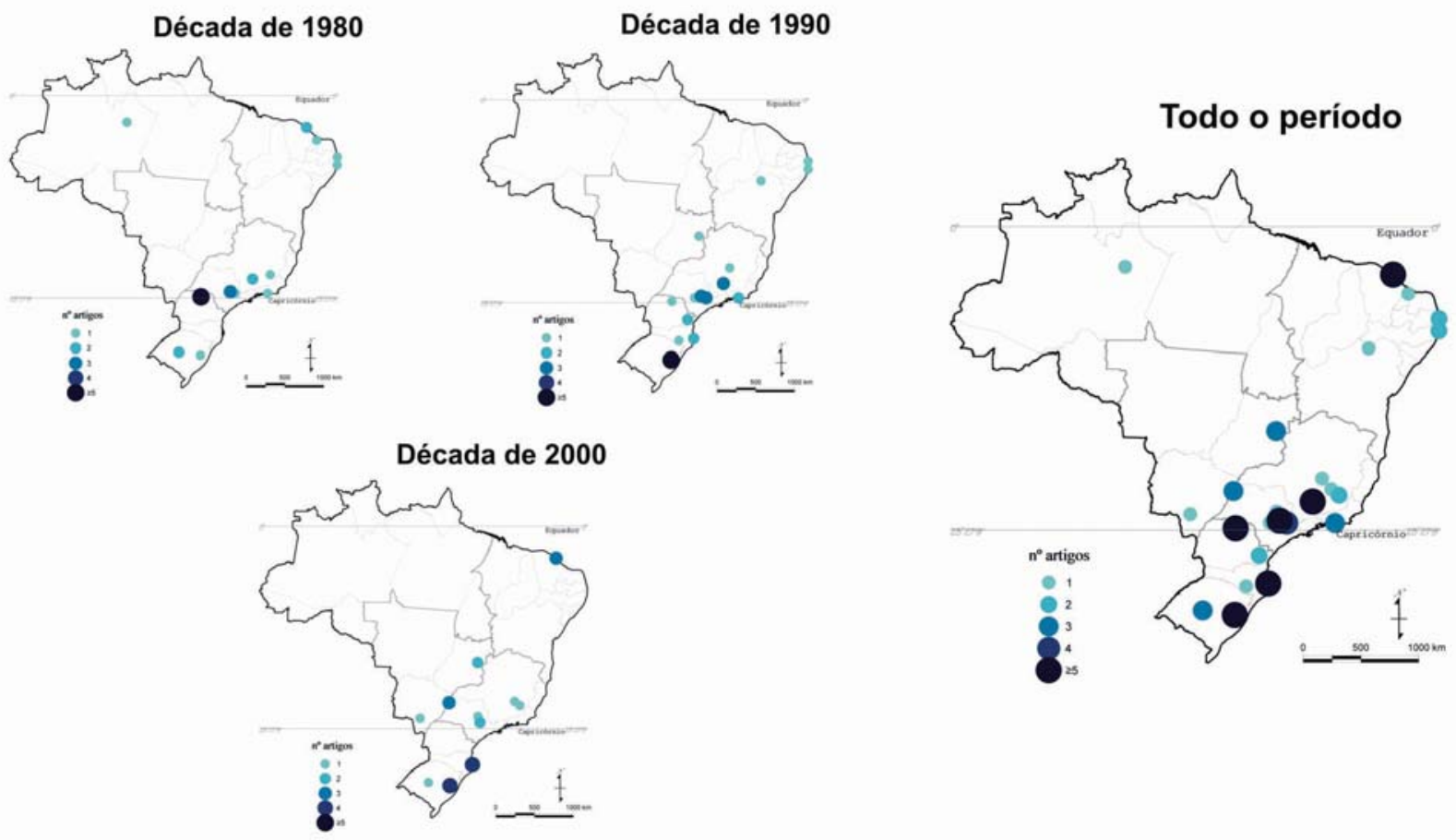

Figura 4. Distribuição espacial da produção de artigos na linha temática "USLE” por década. 


\section{DISTRIBUIÇÃO DA LINHA TEMÁTICA “OUTROS” NO BRASIL}

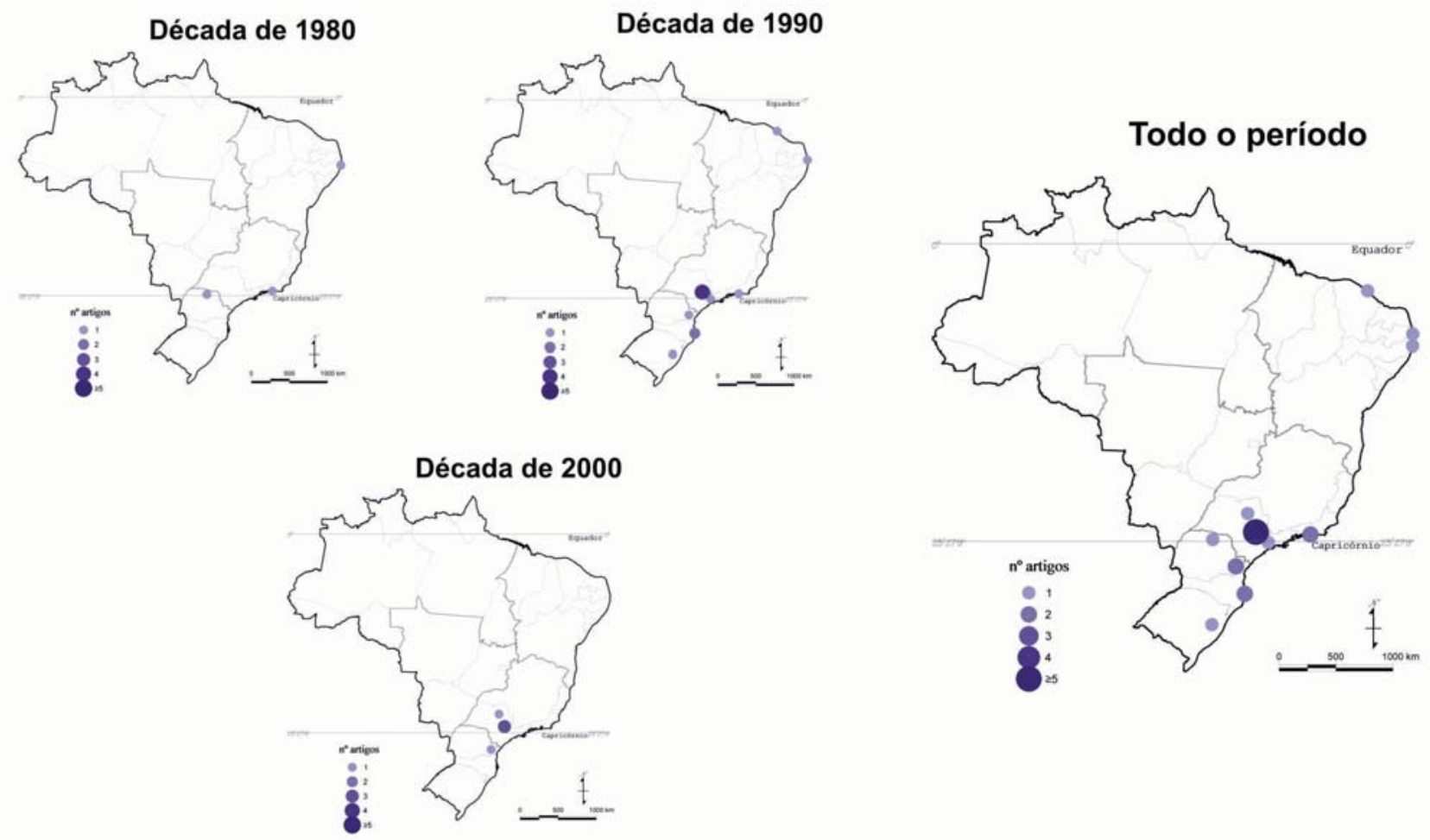

Figura 5. Distribuição espacial da produção de artigos na linha temática “OUTROS” por década.

\section{DISTRIBUIÇÃO DA LINHA TEMÁTICA “PRÁTICAS” NO BRASIL}
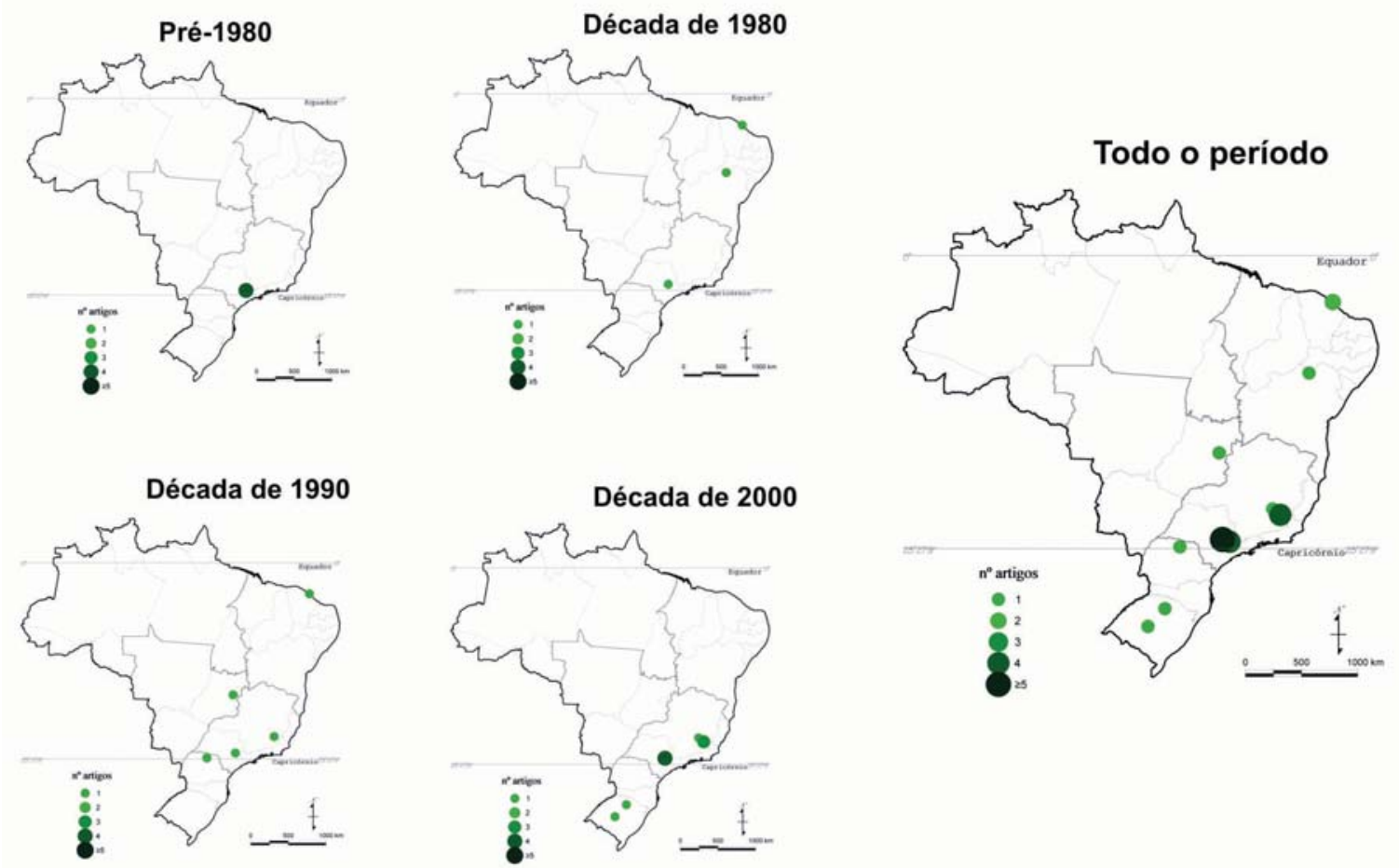

Figura 6. Distribuição espacial da produção de artigos na linha temática "PRÁTICAS” por década. 


\section{DISTRIBUIÇÃO DA LINHA TEMÁTICA “MODELOS” NO BRASIL}
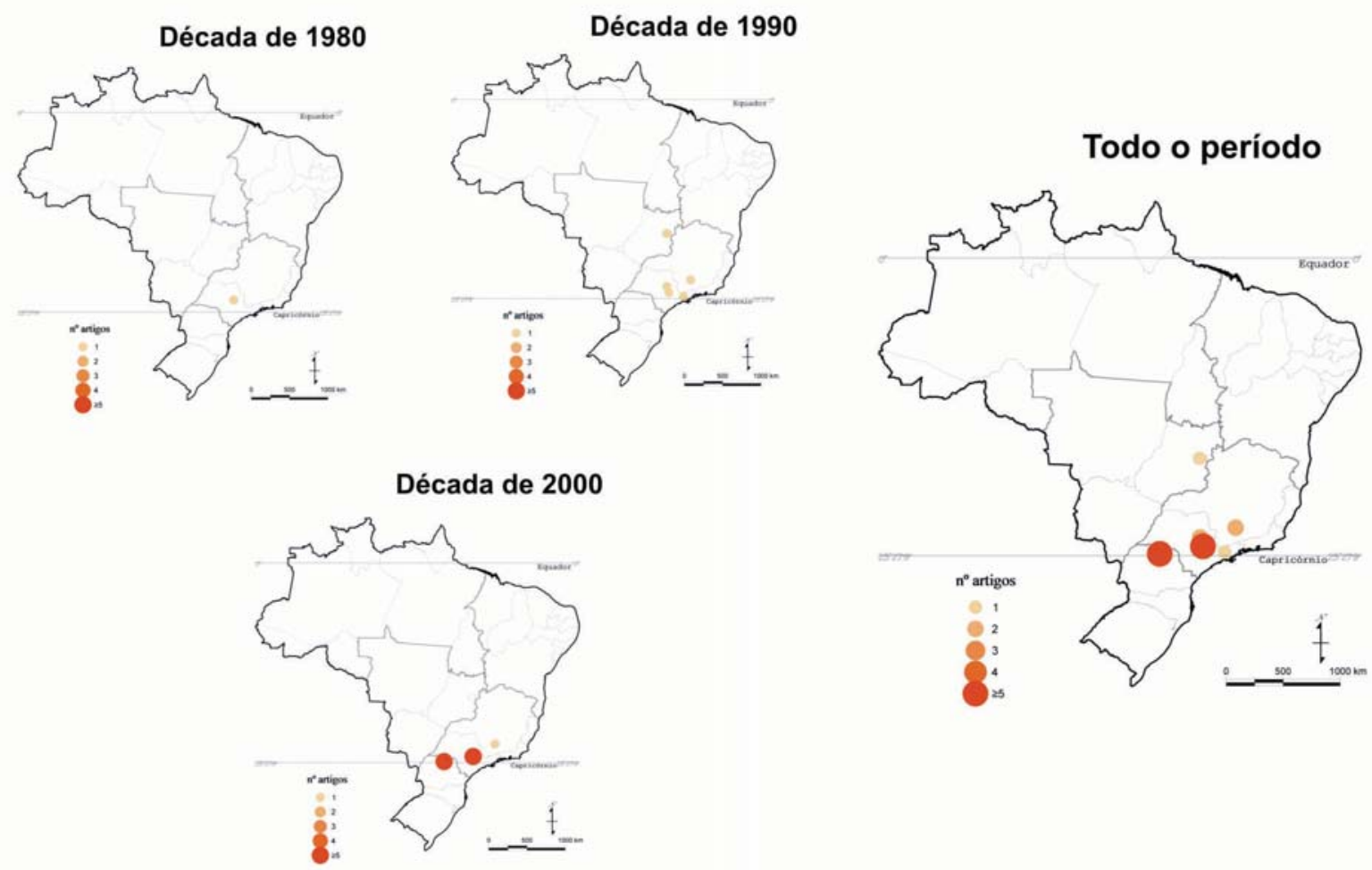

Figura 7. Distribuição espacial da produção de artigos na linha temática “MODELOS” por década.

fortemente influenciado pela pesquisa americana, como para a UFRGS, núcleo de pesquisa consolidado que focou seus esforços científicos em duas linhas temáticas: quantificação dos fatores da USLE e comparações de manejos quanto à perda de solos, não tendo, como observado a seguir, significativa participação na ampliação de outros temas.

A publicação na década de 1970 dos primeiros artigos referentes à USLE, cuja distribuição é mostrada na figura 4, é de autoria da UFRGS, que posteriormente passou a dominar o ranking de publicações com estimativas de perda de solo. A UFRGS ocupou-se principalmente da determinação dos fatores erosividade e erodibilidade. Diferentemente da linha "Comp", o estudo da USLE distribuiu-se mais homogeneamente no espaço, havendo número razoável de instituições com mais de cinco artigos publicados ao final do período estudado. Entretanto, ainda se mantém uma grande variação da produção no tempo.

Alguns picos de publicações em determinadas décadas podem estar relacionados ao desenvolvimento de projetos amplos, que resultam em diferentes formas de análise de dados e apresentação de resultados. Contudo, é possível atribuir a variação na quantidade de artigos abordando a USLE a duas principais causas: o surgimento de núcleos de pesquisa em erosão nas décadas recentes, que parecem ter esse tema como ponto de partida para futuras especializações; e a consolidação de núcleos dedicados a analisar esse modelo de predição nas instituições mais tradicionais em pesquisa sobre erosão.

Para discussão das outras abordagens da erosão linha temática "Outros" (Figura 5) -, a instituição com participação mais significativa foi a USP/ESALQ, que a partir da década de 1990 iniciou e manteve-se como autora principal das publicações dessa linha. Não há distinção de uma abordagem específica na produção científica dessa instituição. Os estudos alternativos de erosão do solo, além de não caracterizarem um enfoque único, são poucos e esparsos, impossibilitando a definição de centros de pesquisa dedicados a essa área.

No desenvolvimento de novos métodos de controle e cálculos da erosão - linha temática "Práticas" (Figura 6) -, as maiores contribuições foram do IAC e da USP, variando no tempo, de uma à outra. O IAC, que sediou as primeiras pesquisas neste tema até a década de 1960, concentrava esforços no conhecimento das práticas conservacionistas recém-desenvolvidas de controle de erosão, como terraceamento, métodos de cultivo e propriedades das culturas no controle da erosão. O período compreendido entre o final da década de 1960 e o início da década de 1990 apresentou decréscimo no número de publicações nessa linha. A partir da década de 1990, a USP passou a liderar a produção científica em análises de técnicas de controle de erosão, relacionada principalmente ao desenvolvi- 
mento de modelos computacionais e análises georreferenciadas. Considerável enfoque a este tema ocorreu recentemente também na Universidade Federal de Viçosa (UFV), ao passo que em outras instituições ele foi tratado apenas uma vez.

Entre as instituições tidas como mais atuantes na pesquisa em erosão, a USP registra dedicação à elaboração e teste de novos modelos de predição (Figura 7), não havendo concentração considerável em nenhum modelo. Contudo, no contexto nacional, a Universidade Estadual de Londrina (UEL) destacase como outra sede de pesquisas com esse fim, onde todos os artigos analisados avaliam a eficácia do método que utiliza Césio137 nas predições, o que permite concluir que ali se consolida um centro de pesquisa sobre esse tema.

Logo, observa-se na pesquisa em erosão acentuada concentração temática, evidenciando uma origem espelhada na experiência norte-americana e embasada na aplicação agrícola. Poucos centros sediaram a maioria das pesquisas. Essas sedes especializaramse em poucas ou uma faceta do estudo da erosão, não havendo, porém, devido a restrições dos métodos adotados neste estudo, a possibilidade de analisar a relação dessa concentração com preferências pessoais dos autores, o que poderia definir outro nível de discussão.

\section{CONCLUSÕES}

1. A pesquisa brasileira sobre erosão acelerada do solo é recente, apresentando maior crescimento e diferenciação a partir de 1980 .

2. A pesquisa brasileira em erosão acelerada do solo está concentrada em poucas instituições, cuja grande maioria está localizada nas regiões Sul e Sudeste do Brasil.
3. Apenas cinco instituições figuram como primeiras autoras em $53 \%$ de toda a produção científica em erosão acelerada do solo.

4. Dois terços das publicações geradas entre as décadas de 1950 e 2000 referem-se aos temas "cálculo e estimativa dos fatores da USLE" e "comparação experimental de manejos na perda de solo".

5. O tema "comparação experimental de manejos na perda de solo" é foco para o desenvolvimento de centros de pesquisa especializados no tema, havendo três instituições que publicaram juntas $50 \%$ dos artigos com tal abordagem.

\section{LITERATURA CITADA}

ARVANITIS, R. \& CHATELIN, Y. Bibliometrics of tropical soil sciences: Some reflections and orientations. In: McDONALD, P., ed. The literature of soil science. Ithaca, Cornell University Press, 1994. p.73-94.

BARRETTO, A.G.O.P.; BARROS, M.G.E. \& SPAROVEK, G. Bibliometria, história e geografia da pesquisa brasileira em erosão acelerada do solo. R. Bras. Ci. Solo, 32:24432460, 2008.

BOARDMAN, J. Soil erosion science: Reflections on the limitations of current approaches. Catena, 68:73-86, 2006.

HARTEMINK, A.E. Developments and trends in soil science. 100 volumes of Geoderma (1967-2001). Geoderma, 100:217-268, 2001.

MCDONALD, P., ed. The literature of soil science. Ithaca, Cornell University Press, 1994.

SANCHEZ, P.A. A review of soils in Tropical Latin America. Raleigh, North Carolina State University, 1972. p.48-64. (Agricultural Experiment Station, 219)

YAALON, D.H. \& ARNOLD, R.W. Attitudes towards soils and their societal relevance: Then and now. Soil Sci., 165:512, 2000 . 